\title{
Water and identity: an urban case study for densification along Los Angeles River's Rio Hondo Confluence
}

\author{
Jeffrey C. Vaglio \\ University of Southern California, Los Angeles, California
}

\begin{abstract}
When Los Angeles was founded in 1781, the mountains, river and shore formed the landscape. Today, street grids and a superimposed network of meandering freeways blanket the valleys while clusters of high-rises emerge periodically to provide underpinnings of the city's identifiable neighborhoods. Only the Los Angeles River is invisible, reduced to concrete-lined drainage channels, denuded of riparian vegetation, bounded by rail lines, hidden behind industrial plants and beneath freeways. What is a river without water?

Throughout landscapes, urban and rural alike, rivers and infrastructure intertwine like tendons to connect cities to natural resources and each other. This dance is particularly evident in an 11-mile stretch of the 51-mile river referred to as Reach 2 where the 710 Long Beach Freeway parallels, elevates, and hurdles the concrete-lined depression of the barren riverbed. Ten cities comprise Reach 2, which fail to garner the attention of Downtown Los Angeles to the north and the Long Beach estuary to the south. As a result of this intermittency, these cities suffer from social and infrastructural neglect, while struggling to develop positive community identity. In modern multi-city metropolitan areas, governmental centers dominate the political infrastructure. Meanwhile, physical infrastructures, such as freeways, often divide these cities. This research seeks to invert these paradigms in an effort to celebrate city identity at political borders, and transform physical divisions into cultural connections.

Research and a design prototype were developed in a unique multi-disciplinary graduate studio environment. Reach 2 is compared to Tokyo to extract potential community identities to support dense and vibrant future development. Additionally, an innovative four-dimensional land-use analysis is conducted across the region to identify voids/opportunities for optimal multi-use development. These investigations culminate in a design prototype at the Rio Hondo Confluence.
\end{abstract}

Conference theme: Urban design studies

Keywords: LA River, density, identity, land-use, master-planning

\section{INTRODUCTION}

Worldwide, cities that were founded on great wellknown rivers are rediscovering and revitalizing their riverfronts. The Los Angeles River has progressed from an unrestrained, meandering river delivering a valuable source of water for early inhabitants, to a major flood control waterway. River revitalizations brings many and varied opportunities - including: recreation, trails, parks, neighborhood identity, nature, jobs, community development, tourism, and civic pride. Long before the first Europeans arrived, the Los Angeles River flowed and was the only source of water for Los Angeles. As Los Angeles grew into the worldclass city it is today, the water was diverted from the river to the pueblo through a complex system of zanjas (ditches), which permitted agriculture to thrive in the region (Gumprecht 1999:369)

The Los Angeles River carried very little water in the dry season - however, flooded frequently during the winter rains. Two major floods in the 1930's killed over
50 people and damaged a significant amount of property. In the 1950's and 1960's, the federal government straightened, deepened, and reinforced the river with concrete (Morrison 2001:128). This concrete structure has saved countless lives and prevented costly property damage - however, this river is now not particularly welcoming to humans or nature.

The Army Corps of Engineers created the concrete encased river bed and banks to serve as flood control, however, the channel remains dry most of the year, except during winter rains. The laminar flow characteristic of the channel serves as an efficient artery to transport stormwater, but with that comes a direct connection for trash, contaminants, and pollution to flow into the Pacific Ocean with little to no filtration through soils or natural processes. Today, environmental groups support the removal of the concrete channel in an effort to restore the River ecology, natural vegetation, and wildlife. River revitalization efforts are also attractive for the resulting parks and riverfront development that are possible in 
what are currently predominantly desolate industrial zones.

The Los Angeles River remains extremely similar to the River Reyner Banham described as "re-routed, tamed, and channelled" (Banham 1971:32). Since documenting his perception, Los Angeles has sprawled outward while improvements to the River ecology remain deprived and unchanged. Los Angeles is a city in perpetual infrastructural crisis, and water infrastructure is no exception. With a state-wide water crisis, environmental concerns, and water demand well in excess of regional water supply, the Los Angeles River is in need of great attention and creative methods of ecological restoration which are innovative, economical and sustainable for future generations.

\section{LOS ANGELES RIVER}

\subsection{Organization}

The Los Angeles River extends 51-miles (82 km) which travel southeast through the San Fernando Valley, to Downtown LA, out it's mouth in Long Beach. The River's primary source-waters flow from the San Gabriel Mountains. The River is divided into six stretches referred to as reaches. Notable reaches include Reach 3 - Downtown, and Reach 1 - Long Beach. The City of Los Angeles contains a 32-mile stretch of the River, the longest of any city (Fig. 1). The other 19 miles are primarily shared between the 10 cities of Reach 2, and Long Beach of Reach 1. Most of the current river revitalization plans encompass key segments within the City of Los Angeles.

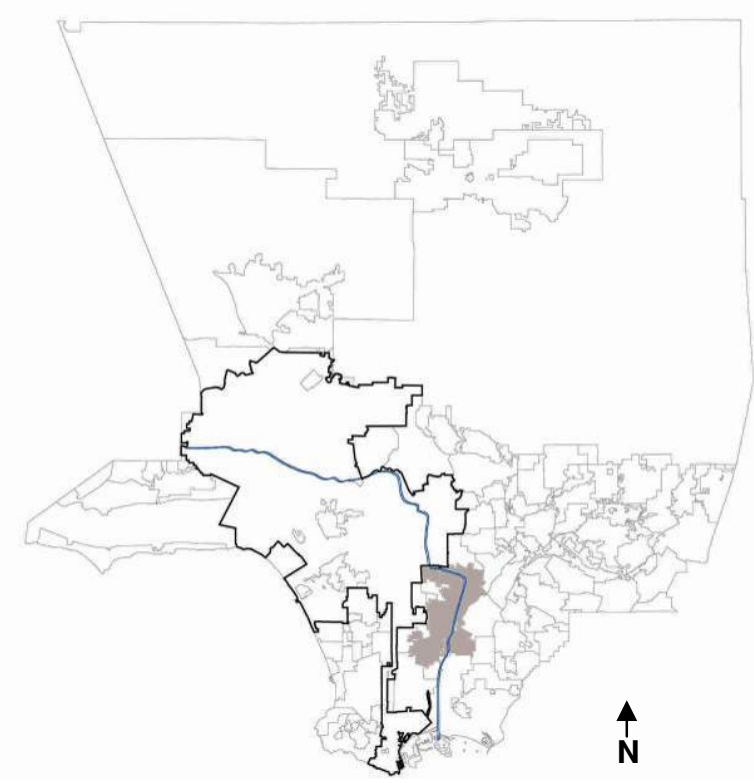

Figure 1: Los Angeles County with city boundaries and the LA River; Reach 2 is highlighted.

\subsection{Existing Revitalization Initiatives}

Visions exist for River ecology to be restored as an integral catalyst to downtown revitalization. Residents and government officials often refer to the San Antonio River Walk as the lively environment to aspire to in the transformation of the symbolically stark channel. Such improvements require coordination of many entities, public and private, infrastructural and natural. How can these visions become realities while still maintaining the flood-control capacity achieved by the original Army Corp of Engineer's design?

In the 2007 Los Angeles River Revitalization Master Plan, the recently established Los Angeles River Master Plan Advisory Committee placed priority to establish the following goals:

\begin{abstract}
Establish environmentally sensitive urban design guidelines, land use guidelines, and development guidelines for the River zone that will create economic development opportunities to enhance and improve River-adjacent communities by providing open space, housing, retail spaces such as restaurants and cafes, educational facilities, and places for other public institutions, improve the environment, enhance water quality, improve water resources, and improve the ecological functioning of the River, provide public access to the River, provide significant recreation space and open space, new trails, and improve natural habitats to support wildlife, preserve and enhance the flood control features of the River, foster a growth in community awareness of the Los Angeles River, and pride in the Los Angeles River.
\end{abstract}

The organizing principles and their supporting goals reflect important values that have been expressed by residents throughout the River Revitalization Master Plan process. Residents have articulated a strong desire for a greener Los Angeles that may be experienced by everyone. Key values shared in the public participation process were environmental responsibility, social and geographic equity, community engagement and support, designs that are based on sustainable economics, and a system-wide perspective toward the Los Angeles River watershed (Los Angeles River Revitalization Master Plan 2007).

Environmental principles and values - such as restoring natural systems and remaking human environmentshave exerted a strong influence on the Master Plan. The Los Angeles River is both a real and symbolic source of life for the City (Gumprecht 1999:369). As such, restoring the River's environmental functions and making it the spine of a stronger green space system are integral to the planning effort.

The revitalization of the River cannot transpire without extensive and enthusiastic community encouragement. This Plan was developed by and for the residents of the City, and requires their support to be successfully executed. The City is privileged to have strong support for River revitalization at every level of government. As the project plan is implemented and progresses, it is imperative that this support be continued to guarantee a permanent dedication to River revitalization.

Efforts are happening throughout the watershed to supply financial support for water-quality compliance activities, ecosystem restoration, community 
reinvestment, transportation improvements, and for recreational amenities. Lessons from other cities that have revitalized their riverfronts illustrate that changes of the type recommended here necessitate confidential/private investment and initiative (Los Angeles River Revitalization Master Plan 2007). Design standards and guidelines for development within a proposed River Improvement Overlay (RIO) will be established to support the Master Plan, so that reinvestment may occur in an environmentally-sensitive and sustainable manner.

Efforts to advance environmental circumstances within the watershed of the City and County of Los Angeles have been occurring for decades. While this Master Plan balances and strengthens these efforts, it is imperative to comprehend that it single-handedly cannot resolve all of the watershed's problems (Programmatic Environmental Impact Report 2007). Since the context for the Master Plan is the River Corridor within the City of Los Angeles, it is beyond the scope of the Master Plan to provide detailed solutions to watershed-wide issues, such as water quality, habitat values, densification, industrial land use, and affordable housing. The Master Plan addresses these matters within the context of the River Corridor, and makes recommendations when connections exist to other planning efforts, such as those for water quality, habitat corridors, and flow reduction (Los Angeles River Revitalization Master Plan 2007). The proposed 3tiered River management structure can facilitate longerterm partnership that would promote a broader conversation and more regional benefits.

Implementing the Los Angeles River Revitalization Master Plan will require the ongoing engagement and support of the many people and groups that have collaborated in its creation. The River management structure that is proposed in the Master Plan is designed to create a short- and long-term strategy that is fundamental to moving this proposed agenda forward. The proposed structure is designed to address River revitalization in a holistic manner, focusing on governmental management, entrepreneurial stewardship through the Revitalization Corporation, and philanthropic leadership through the River Foundation.

The Los Angeles River Revitalization Master Plan provides both a long-term vision and implementation guidance for revitalizing the River. It is aimed as an outline, creating the vision and guiding principles for executing, yet permitting considerable opportunity for the details of specific projects to be shaped through community and neighborhood strategy developments.

\subsection{Opportunities for advancement}

The existing revitalization plans confine their scope to the segments of the Los Angeles River within the City proper. The cities most effected by the decisions and actions of the City of Los Angeles are the cities immediately downstream - specifically the 10 cities of Reach 2. These cities are home to nearly 500,000 people, of which, $46 \%$ are foreign born. These communities suffer from social neglect due to their intermittency between the Downtown Los Angeles and the Port of Long Beach. Additionally, the cities are fragmented amongst themselves, and can be characterized by poverty, unemployment, crime, and exposure to unhealthy levels of air and water pollutants as a result of smog and proximity to the Alameda Corridor which transfers imported goods from the Port by rail and truck throughout the country.

In order to revitalize the River in the holistic manner described in the Master Plan, it is necessary to consider the whole River. An improved level of collaboration amongst the smaller municipalities is required to successfully implement a true River revitalization effort across these conflicted communities. Before implementation begins, there are tremendous opportunities for advancement in the Master Plan to integrate the entire river and proximate communities.

\section{OBJECTIVES}

\subsection{Design/Research Studio}

Investigate and propose innovative master plans for the entire 51-mile Los Angeles River. The designs should invigorate discussion and challenge the traditional paradigm of river revitalization models.

\subsection{Reach 2}

Develop a master plan for the Reach 2 (Fig. 2) which creates community identity, density and a synergistic integration of infrastructure and landscape.

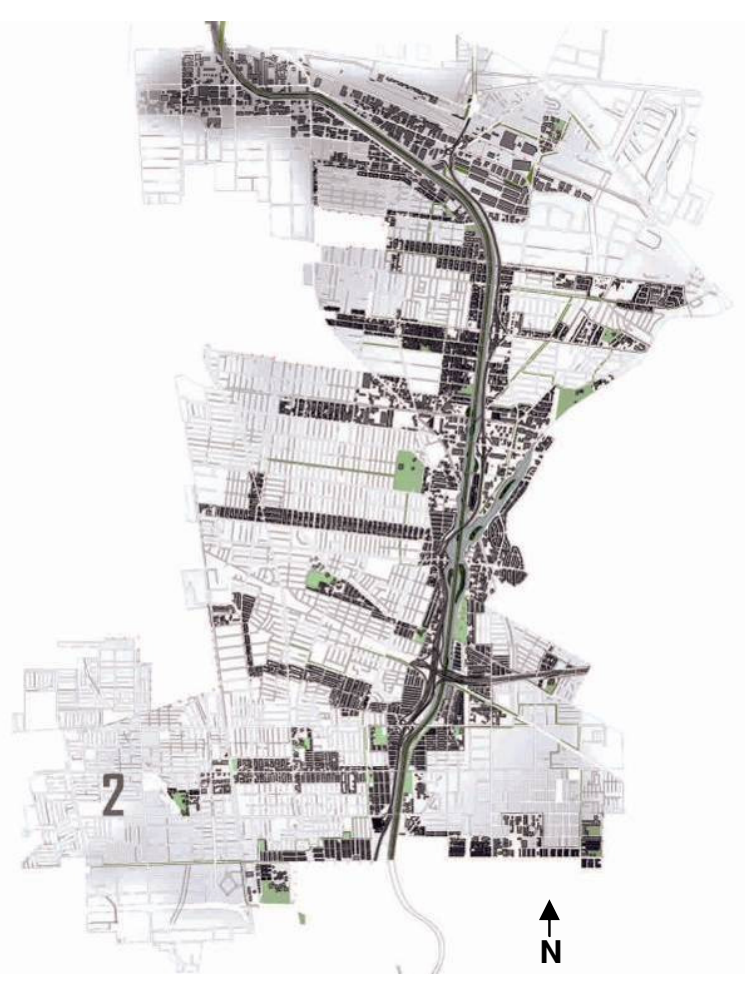

Figure 2: Reach 2's master plan scope. 
Additionally, develop a prototypical architecture for three significant typologies to support a sustainable River community.

\section{METHODOLOGY}

\subsection{Design/Research Studio}

The 51-mile Los Angeles River was divided amongst six teams of three graduate students. Each team chose one of the six reaches of the River, resulting in six individual, yet interdependent projects. The research and design was conducted over an 18-week semester with a multi-disciplinary, collaborative instruction model (Fig. 3).

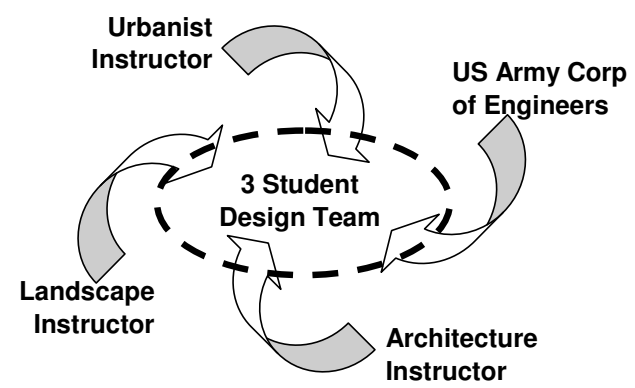

Figure 3: Conceptual studio instructional model.

Each design team received instructional advisement regularly from at least one of the individuals described above, and often times two or more. The urban instructor was present for approximately $75 \%$ of the course/review sessions, landscape $50 \%$, architecture $25 \%$, and external Army Corp of Engineers-Los Angeles River representatives were present every 4weeks for significant review sessions. This model of diverse advisement resulted in research-driven design initiatives which emphasized ecology and dense hybriddevelopment. The instruction and process proved comprehensive and innovative.

\subsection{Reach 2}

A master plan was developed for Reach 2 by executing the following:

- Identify the master plan scope through development of an urban conceptual logic

- Develop a strategy to promote density

- Characterize the existing nature of each city

- Research and profile a dense, urban precedent

- Perform a knowledge transfer to suggest future interdependent Reach 2 city identities.

Three prototypical hybrid architectures were developed by executing the following:

- Locate a site which encompasses primary topics

- Develop programs based on the needs of the River, infrastructure, and adjacent city identities

- Design architectural elements which are integral to the landscape and sustainable community.

The master plan and hybrid architectures are described in greater length in following sections.

\section{CONCEPTUAL DEVELOPMENT}

The master planning development began with a conceptual strategy which first located existing physical divisions within Reach 2 . These physical divisions included, but were not limited to, freeways, railroads, and the River. Next, the city boundaries for each of the 10 cities were located. The corridors along these borders are often lost between governments, but this concept seeks to celebrate the boundaries as areas to project positive community identity and bridge boundaries with infrastructural connections. Diagrammatically, these two are inverted, to create a concept which makes invisible boundaries visible, and transforms physical divisions into infrastructural connections. The master plan scope is narrowed down to the physical divisions, such as the river and freeway, and the infrastructural connections along city borders (Fig. 4). When superimposed, a series of programmatic opportunity areas is revealed.

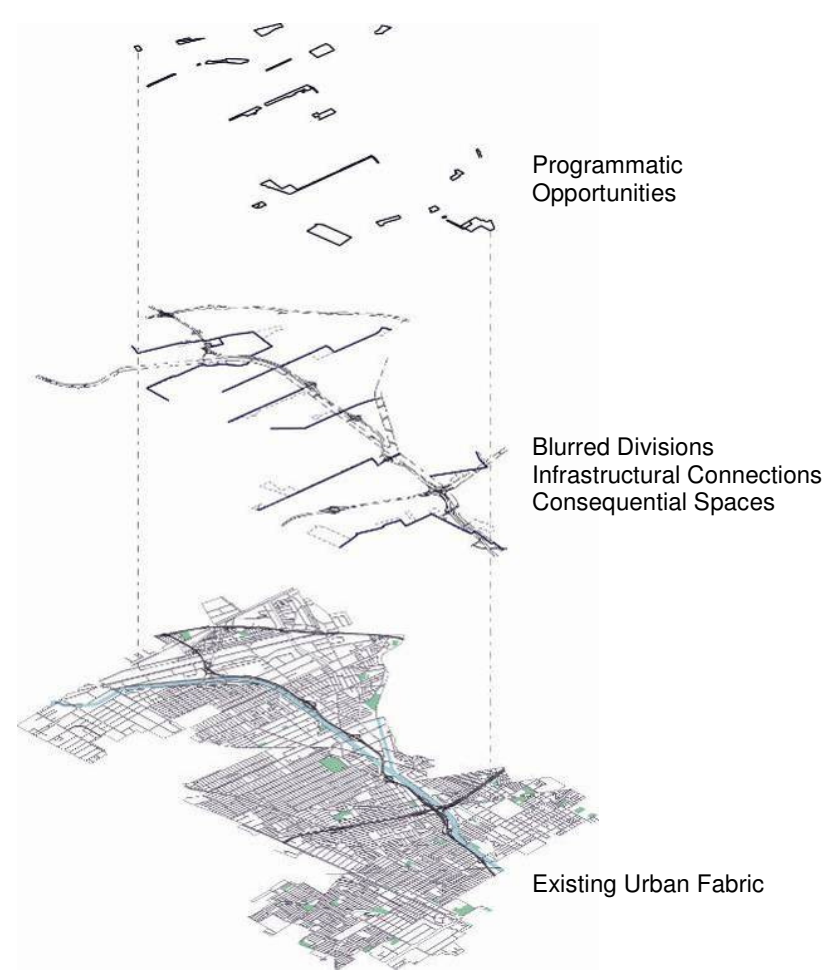

Figure 4: Reach 2 conceptual development layers.

\section{REACH 2}

Reach 2 is comprised of an 11-mile stretch of the Los Angeles River through 10 cities (from north to south) Vernon, Commerce, Maywood, Bell, Bell Gardens, Cudahy, South Gate, Lynwood, Compton, and Paramount. These cities, and the Reach as a whole, fail to garner the attention of Downtown LA to the north and the Long Beach Estuary to the south. In order to propose methods of urban densification and identity development, the existing context, and the role of the River within these cities, was researched. 


\subsection{Population Increase}

The population of Los Angeles has been increasing at a steady rate of $3 \%$ each year. This continual sprawl patterns however have yet to create substantial density within the Los Angeles agglomeration. The density of each city within Reach 2 varies drastically due to the residential nature of cities like Maywood, compared to primarily industrial land use in Vernon (Table 1).

Table 1: Reach 2 cities' population profile.

\begin{tabular}{ccc}
\hline City & $\begin{array}{c}\text { Population } \\
(2007)\end{array}$ & $\begin{array}{c}\text { Density } \\
\text { (People/Sq Mile) }\end{array}$ \\
\hline Vernon & 81 & 18 \\
\hline Commerce & 13,537 & 2,050 \\
\hline Maywood & 28,714 & 24,341 \\
\hline Bell & 37,332 & 15,157 \\
\hline Bell Gardens & 45,285 & 18,167 \\
\hline Cudahy & 24,873 & 22,352 \\
\hline South Gate & 98,434 & 13,435 \\
\hline Lynwood & 71,061 & 14,678 \\
\hline Compton & 95,701 & 9,445 \\
\hline Paramount & 56,369 & 11,955 \\
\hline
\end{tabular}

Los Angeles is approaching crisis as environmental concerns such as increasing global carbon emission and temperature are compounded over the existing infrastructural (transit, water, etc.) issues the region faces. As Reach 2's population increases between now and the year 2050, $25 \%$ of the total land mass must become green space in order to maintain the existing green space per capita. This expansion (and not contraction) of urban open space square footage will drastically add to the densifying effect related to population increase.

\subsection{Commuting Profile}

A city's tax revenue is directly affected by its working population's location of employment. Currently, the majority of workers in Reach 2 travel outside of its 10 cities for work (Table 2). If the new master plan proposal reduces travel distance to work by $50 \%$ by creating employment opportunities within the region, the entire Reach will benefit from over $\$ 200,000,000$ in tax revenue annually through spending retention.

Table 2: Reach 2 cities' commuting profile

\begin{tabular}{ccc}
\hline City & $\begin{array}{c}\text { Local Resident } \\
\text { Worker, }(\%)\end{array}$ & $\begin{array}{c}\text { Commute Time } \\
(\text { min. })\end{array}$ \\
\hline Vernon & 47.2 & 23.0 \\
\hline Commerce & 21.1 & 25.7 \\
\hline Maywood & 8.3 & 29.2 \\
\hline Bell & 10.5 & 28.5 \\
\hline Bell Gardens & 10.9 & 30.1 \\
\hline Cudahy & 7.3 & 29.8 \\
\hline South Gate & 11.9 & 30.5 \\
\hline Lynwood & 11.6 & 30.7 \\
\hline Compton & 15.3 & 29.0 \\
\hline Paramount & 14.8 & 27.1 \\
\hline
\end{tabular}

In order to make a reduction to the travel time of Reach 2 with simultaneous population increase, the existing commute patterns must be understood. Each city's commuter splat is mapped to show the impact each city currently has across Los Angeles County (Fig. 5). The mapping factors in destination, and percentage of residents within the city commuting to that destination. A best-fit curve is used to bound the data points, thus generating the commuter impact area for each city. This analysis reveals that the City of Lynwood has the greatest commuter impact across the region, while Vernon has the smallest.

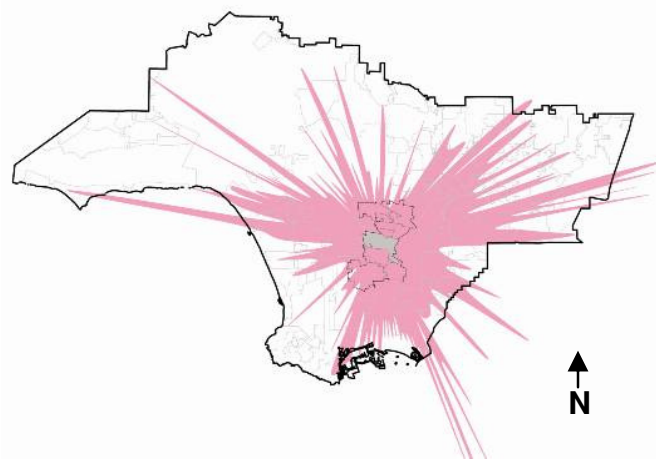

Figure 5: Commuter splat summary for South Gate.

\subsection{City Profile Mapping}

The potential for infrastructural interdependency requires a strong understanding of each component's existing strengths. In an effort to extract existing identities from the 10 cities of Reach 2, a zoning profile (Table 3) and an amenity profile mapping (Figure 6) reveal concentrations, linear connections, and areas of particular amenity emphasis. The zoning profile summarizes the land-use dedicated to each zoning category (i.e. industrial or residential) as a percentage of the total city land area.

Table 3: Reach 2 cities' zoning profile. Data presented as a percentage (\%) of total land area.

\begin{tabular}{|c|c|c|c|c|c|c|c|}
\hline$\stackrel{\overrightarrow{0}}{0}$ & 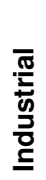 & $\begin{array}{l}0 \\
\frac{0}{2} \\
\frac{0}{0} \\
\frac{\pi}{2} \\
\frac{1}{\pi} \\
\Sigma\end{array}$ & 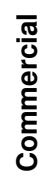 & $\frac{0}{\frac{0}{2}}$ & 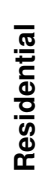 & 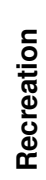 & 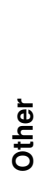 \\
\hline Vernon & 86 & 0 & 6 & 0 & 0 & 0 & 8 \\
\hline Commerce & 0 & 68 & 1 & 5 & 7 & 0 & 19 \\
\hline Maywood & 6 & 0 & 9 & 2 & 59 & 1 & 23 \\
\hline Bell & 1 & 0 & 17 & 3 & 78 & 1 & 0 \\
\hline Bell Gardens & 0 & 7 & 17 & 0 & 68 & 3 & 5 \\
\hline Cudahy & 0 & 0 & 20 & 0 & 78 & 2 & 0 \\
\hline South Gate & 17 & 0 & 8 & 9 & 52 & 0 & 14 \\
\hline Lynwood & 0 & 18 & 10 & 4 & 67 & 1 & 0 \\
\hline Compton & 0 & 25 & 10 & 2 & 58 & 5 & 0 \\
\hline Paramount & 0 & 31 & 6 & 3 & 53 & 4 & 3 \\
\hline
\end{tabular}

Additionally, the amenity profile mapping locates and quantifies the services available within each of Reach 2's ten cities. This reveals strengths, weaknesses, and potential interdependent relationships amongst the cities. For example, the city of South Gate has a much 
greater emphasis on education facilities than adjacent cities Cudahy and Maywood. These cities rely on South Gate for such facilities, and therefore, the city has characteristics of an educational core.

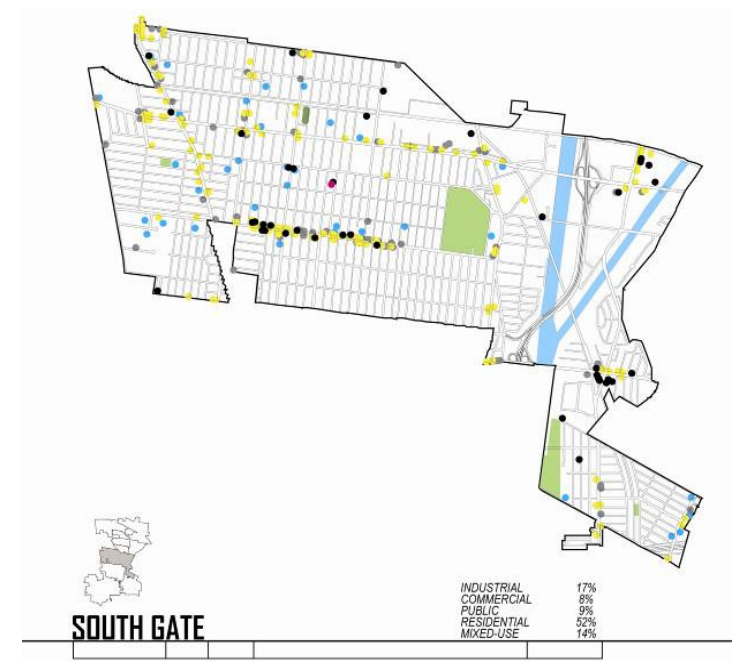

Figure 6: City of South Gate amenity profile mapping.

Google $^{\mathrm{TM}}$ Earth software was used to identify and locate amenities and services for each city within the following categories; cultural (museums, auditoriums, community centers, and galleries), retail (department stores, clothing, books, records/cd, and sporting goods), entertainment (restaurants, café/bakeries, bars, amusement places, movie theatres, and video rentals), domestic retail (grocery stores, supermarkets, banks, gas stations laundry, pharmacies, and gyms), education (art/music, preschool, K-12, college, business, and computer), and other (hospitals, and government facilities). The results are summarized:

Table 4: Reach 2 cities' population profile.

\begin{tabular}{|c|c|c|c|c|c|c|}
\hline$\underset{0}{*}$ & $\begin{array}{l}\bar{\pi} \\
\frac{\pi}{5} \\
\frac{ \pm}{3}\end{array}$ & $\begin{array}{l}\overline{\bar{\pi}} \\
\bar{d} \\
\widetilde{x}\end{array}$ & 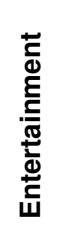 & 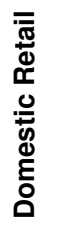 & 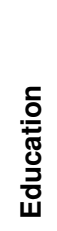 & 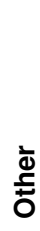 \\
\hline Vernon & 1 & 3 & 6 & 15 & 0 & 1 \\
\hline Commerce & 0 & 1 & 11 & 15 & 0 & 5 \\
\hline Maywood & 2 & 8 & 18 & 20 & 2 & 3 \\
\hline Bell & 2 & 2 & 15 & 25 & 0 & 2 \\
\hline Bell Gardens & 0 & 14 & 74 & 33 & 12 & 0 \\
\hline Cudahy & 1 & 4 & 6 & 12 & 0 & 1 \\
\hline South Gate & 1 & 36 & 185 & 93 & 35 & 1 \\
\hline Lynwood & 1 & 31 & 127 & 67 & 26 & 1 \\
\hline Compton & 2 & 5 & 98 & 75 & 25 & 1 \\
\hline Paramount & 0 & 7 & 61 & 32 & 14 & 1 \\
\hline
\end{tabular}

City profile mappings often reveal strengths or amenity axis, but another analytical method is required for cities which lack strengths, and possess no clear sense of community identity.

\section{DENSITY AND IDENTITY}

In order for the 10 cities of Reach 2 to prosper in the future will require sustainable growth by means of higher population density, an increased level of economic retention, and multi-city interdependency infrastructures. Instead of developing interdependent city relationships through a subjective process, the design team studied an existing high-density city to project what the identities should be in the future for the Reach as a whole.

\subsection{Tokyo Study}

Tokyo was examined as a high-density case study because of its similar density to Reach 2's projection for 2050, and for the unique identity of and relationships between its wards. The 23 special wards of Tokyo were studied, mapped and diagrammed as relationships between infrastructures, amenities, and open space (Fig. 7). Unique characteristics for many of the wards were identifiable and informed the design team of integral elements of a successful, high-density environment.

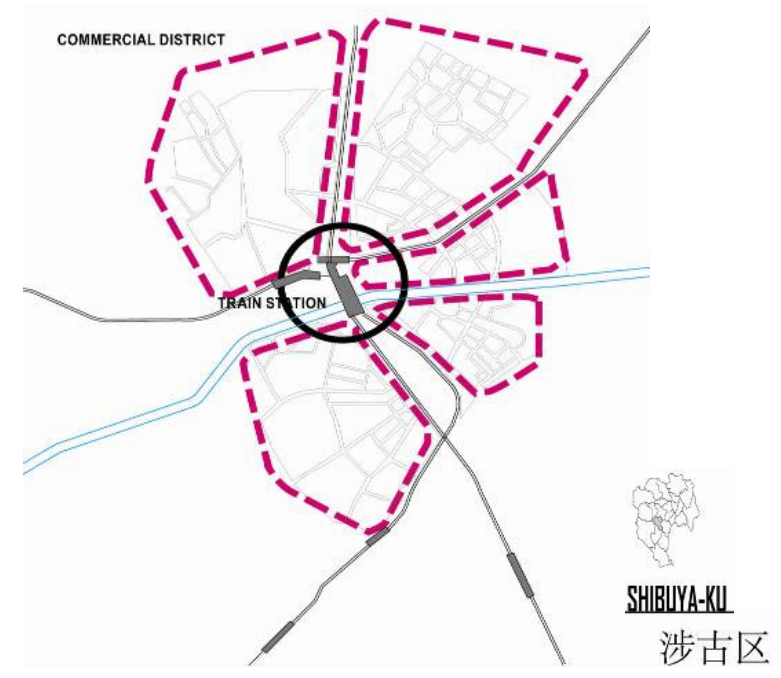

Figure 7: Tokyo study excerpt: relationship diagram of Shibuya-Ku's commercial district.

\subsection{Identity}

The previously developed city profile mappings were compared to the Tokyo ward relationship diagrams to see what community identities may be possible using existing infrastructure and strengths. This knowledge transfer then created an interdependent Reach 2 with 10-cities, each with individual strengths to compliment those of adjacent cities and existing infrastructure. Several examples of new proposed city identities include Commerce as a governmental center, South Gate as the educational core, Compton as an international business corridor, and Lynwood as an Entertainment Center for the Reach. This research strategy, including profile mapping and precedent study, resulted in a diversity of applied city identities, and optimized existing strengths of each community. 


\section{MASTER-PLANNING STRATEGIES}

The design team developed a four-dimensional landuse analysis method to optimize environments through collisions of necessary infrastructure and programmatic voids. This method sought to evolve beyond the traditional paradigm of zoning designation as a twodimensional mapping, an evolution which is necessary for the high-density environments of the future.
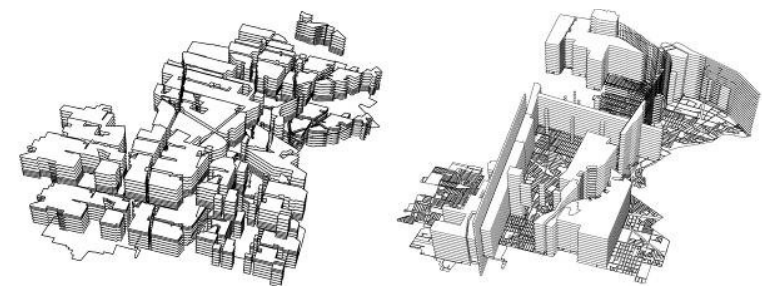

Figure 8: Reach 2 four-dimensional land-use analysis: residential (left) with Tokyo Injection overlay (right).

The master conceptual development proposes a network of optimized programs at all locations along the scope of city borders, and along physical divisions, such as the river and freeways. When the conceptual and research studies are overlaid in a threedimensional model with a z-axis mapping time, programmatic windows are located both physically, and within a time frame. The vertical axis acts as a time scale allowing existing zoning to be mapped as a programmatic element through the course of a 24-hour day (Fig. 8). Allowing programs to exist within a subdivided time range generates unique hybrid programs which optimize the site and land-use performance. Using time as the fourth-dimension within environment mapping advances beyond volumetric relationships and designations of space, to a realm of sustainable performance environments.

\section{DESIGN CULMINATION}

The Rio Hondo Confluence is a collision of a 710freeway interchange, Los Angeles River, and Rio Hondo River. The site was selected as a prototypical study for its shared boundaries between South Gate, Lynnwood, Paramount and Compton communities, and its complex interaction between the river and freeway (Fig. 9 and 10). This hybrid development is a prototype of how such an overlapping river and freeway interchange might exist in complex harmony.

Programmatic optimization is achieved between engineered islands by a series of inflatable dams that retain water in evaporative cooling zones adjacent to residential and educational buildings, while allowing for riverbed occupancy in intermediate dry zones. For example, in the riverbed zone adjacent to the school, synthetic field turf is used as recreational space during the great majority of the year, when the river is at minimal capacity (Fig. 12). The islands subdivide the 300-foot gap of the existing channel, mending communities across a public river landscape.

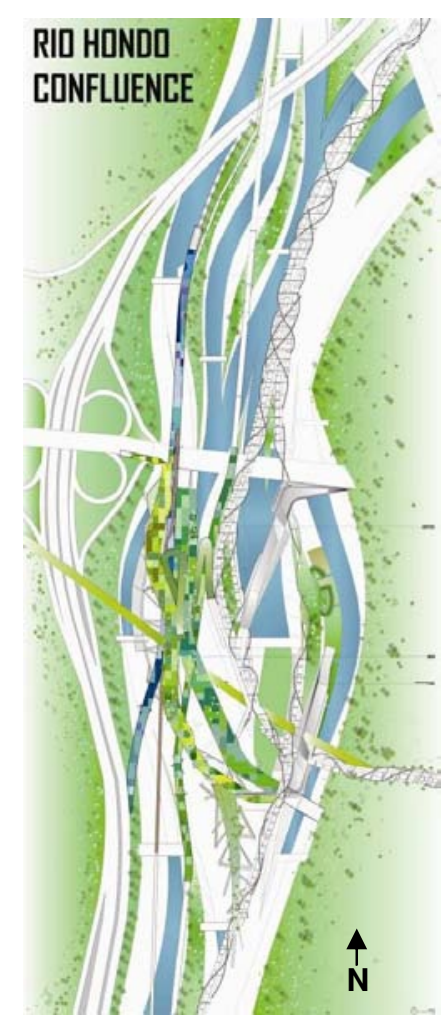

Figure 9: Proposed Rio Hondo Confluence site plan.

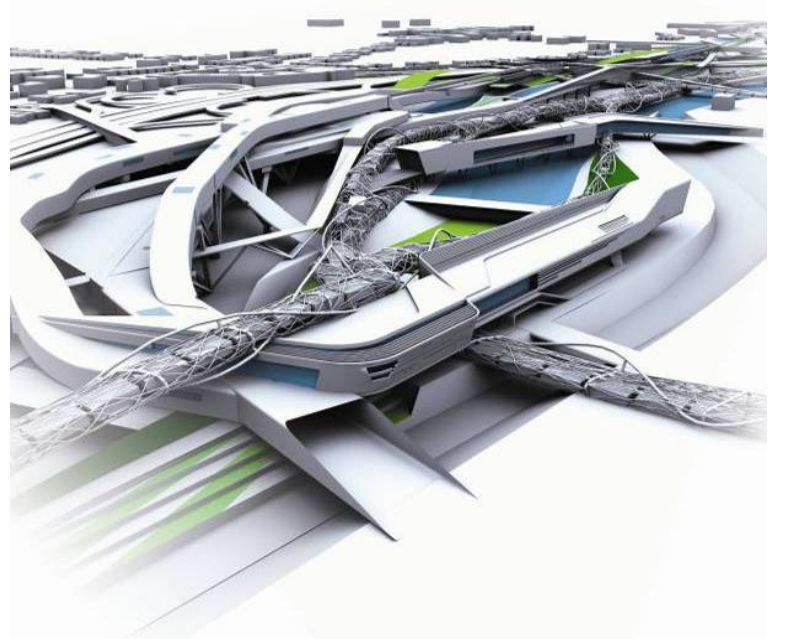

Figure 10: Rio Hondo Confluence's hybrid overlapping of infrastructure, landscape, and programming.

This collision of two traditionally isolated programs is part of a proposed paradigm shift which is inevitable as population density increases, and necessary infrastructures are upgraded or constructed. This shift forces new adjacencies which have previously been unthinkable, but will be necessary as societies continue to concentrate in metropolitan areas. The following hybrid programs are prototypes explored at the Rio Hondo confluence: 


\subsection{Transit + Farm}

To accommodate the anticipated population growth, new transit centers and mass transportation systems are in great need for everyday travel, and an estimated 1 billion hectares of new land will be needed to grow enough food to feed them.

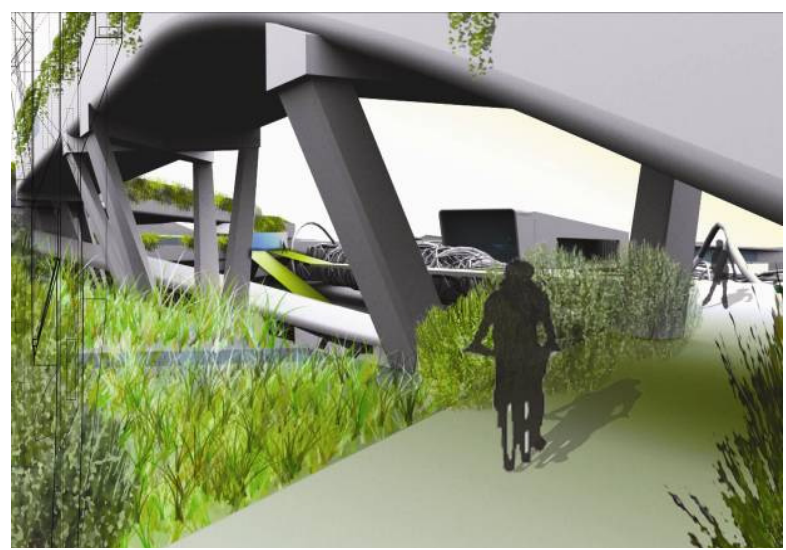

Figure 11: Interaction of landscape and infrastructure.

\subsection{Pedestrian + Residential}

Open green space within the ultimate interchange is accessible through linear housing developments which double as a pedestrian network. By proximity and linkage, new housing brings life and activity to the river in provocative human and nature interaction (Fig. 11).

\subsection{Water + Identity}

South Gate is the educational core of Reach 2, and therefore a water treatment plant is paired with an education facility. As a hybrid program, the treatment facility/school is always working programmatically for the city's residents. By combining two inverse time block activities, the water treatment would occur at night, offset from school hours. This overlap of operations is vital to Reach 2 as population increases.

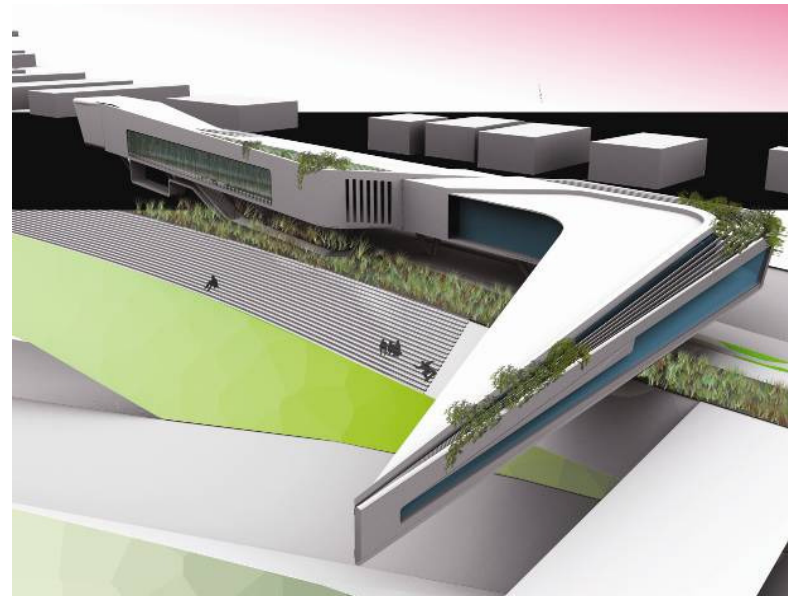

Figure 12: $\mathrm{K}-12$ school atop a water treatment berm.

\section{CONCLUSION}

The design studio model was successful in integrating the entire River within a complex multi-disciplinary environment of research and exploration. Specifically, Reach 2's research and design proposal challenge traditional master planning methods, and addresses density and land-use, something that was beyond the scope of the Revitalization Master Plan. The embryonic methods and designs are in some ways conflicted, but they are the bi-product of innovative alternative design and planning strategies.

As urban centers sprawl or densify, water remains the foundation upon which great cities, like Los Angeles, are built. Networks of streams and rivers are every bit arterial as the freeways which bridge them. Improving urban connective tissues requires an appreciation for the role of water and a hybrid-urbanism where the boundary is blurred between engineering and landscape design to generate working landscape processes for a sustainable future.

\section{ACKNOWLEDGMENT}

The Reach 2 design team was comprised of Yunnan Allen, Jeffrey Vaglio, and Zhi-ya Wu. Their research and design contributions are gratefully acknowledged. Research and design advisement was received from Professors Eui-Sung Yi, David Fletcher, Selwyn Ting, and the Army Corps of Engineers - Los Angeles, throughout the development of this project.

Statistical data for each city was derived from the U.S. Department of Labor - Bereau of Labor Statistics.

\section{REFERENCES}

Bahnam, R. 2000. Los Angeles: The Architecture of Four Ecologies. University of California Press: Berkley, California.

Gumprecht, Blake. 1999. The Los Angeles River : its life, death, and possible rebirth. Johns Hopkins University Press: Baltimore, Maryland.

Los Angeles River Revitalization Master Plan. 2007. Los Angeles Ad Hoc River Committee: Los Angeles, California.

Morrison, Patt. 2001. Río L.A. : tales from the Los Angeles River. Angel City Press: Santa Monica, California.

Programmatic Environmental Impact Report Programmatic Environmental Impact Statement for the Los Angeles River Revitalization Master Plan. 2007, U.S. Army Corps of Engineers/City of Los Angeles: Los Angeles, California. 